\title{
Religion's impact on Ramadan fasting for patients with diabetes mellitus: A review of evidence
}

\author{
Imad eddin Rahamtalla Musa* \\ Royal Commission Hospital at Jubail Industrial City, KSA
}

\begin{abstract}
Introduction: Ramadan is the holy moon month for Muslims during which they fast from predawn to after sunset. Ramadan is a divine duty for all healthy Muslim adults. There is a large number of Muslims with type 2 diabetes mellitus, who have the low-to-moderate risk that is associated with fasting.

Aim: This study aims to explore the role of the Islamic religion in promoting safe Ramadan fasting for Muslim patients of diabetes mellitus.

Method: A systematic search of studies relating to diabetes mellitus during Ramadan fasting was conducted between the $1^{\text {st }}$ of January 1990 and the end of February 2019 for relevant studies, using the following databases: PubMed and Google search engine. The words "religious", "fasting", "Ramadan" and "diabetes mellitus were used.

Result: A total of 153 citations were initially identified. One hundred four were removed for failing to address the aim of the study, duplication, lack of proper citation, and poor use of language. After screening titles and abstracts, 49 full-text articles were retrieved for eligibility analysis. Nine studies focused on the importance and positive effects of religion on fasting for these patients, fifteen studies concentrated on the exemptions during Ramadan, six studies evaluated the reasons for fasting among exempted persons, seven studies corrected some wrong ideas about fasting, religious education (five studies) (lack of knowledge and its importance) and the effect of cooperation between religion scholars and healthcare providers (thirteen studies). Six studies covered more than one item.
\end{abstract}

Conclusion: Islamic religious teachings and medical recommendations can strengthen each other to promote safe adherence to divine duty for patients with diabetes mellitus during Ramadan.

\section{Introduction}

Ramadan is the ninth Arabic month and is believed to be a holy month for Muslims. Moreover, fasting during this month is one of the pillars of Islamic practice. In 2015, the numbers of patients with diabetes mellitus and impaired glucose tolerance globally were estimated to be 415 and 318 million adults, respectively. Consequently, this group of patients is expected to increase by $55 \%$ by 2040 [1]. Likewise, the number of patients with diabetes in the Middle East and Africa as well as South East Asia regions, where there is a considerable number of Muslim inhabitants, is predicted to exceed double the recent number by 2040 [1]. Furthermore, about 1.7 billion Muslims worldwide are committed to the divine commands of fasting during Ramadan [2]. The prevalence of fasting during Ramadan was $93.4 \%$, the average number of fasting days was 24.1 days, and those above 54 years had a significantly higher tendency to fast during Ramadan than the younger age groups [3]. On the other hand, a considerable percentage (71.5\%) of patients were able to fast during Ramadan without interruption [4]. In fact, some patients with type $1(43 \%)$ and type 2 (79\%) diabetes mellitus preferred to fast during Ramadan irrespective of the increased risk of significant hypoglycemia [5]. Most of these patients are considered as high risk for fasting. Likewise, over $55 \%$ of patients treated with insulin analog and over a third with mixed insulin insisted on fasting during Ramadan: $54.9 \%$ and $55.8 \%$ were type 1 and type 2 diabetes mellitus, respectively [4]. Wide fluctuations in blood sugar levels were observed among patients with diabetes mellitus during Ramadan fasting, which increased the risk of acute metabolic complications: hypoglycemia, hyperglycemia, diabetic ketoacidosis, dehydration, and thrombosis
[4-7]. In contrast to what was mentioned above, Ramadan fasting for healthy individuals was associated with significant weight reduction, estimated glomerular filtration rate, improved cardio-metabolic parameters, lower systolic and diastolic blood pressure [8-10]. Not only fasting Ramadan is based on physical fitness but also religious devotion is a huge factor. Fasting at Ramadan is obligatory upon every Muslim of both sexes who is sane and is not sick or on a journey [11]. On the other hand, sick persons, pregnant women and nursing mothers, women in menses or with post-natal bleeding, people traveling during Ramadan, children and those who lack insight are not allowed to fast [12-14]. The role of the religion was not well articulated until the recent decree issued at the meeting of the Council of the International Islamic Fiqh Academy of the Organization of Islamic Conference at its nineteenth session held in the Emirate of Sharjah, The United Arab Emirates, between 26th and 30th April 2009. It was the first brick that fixed the cooperation between the Islamic Organization for Medical Sciences (based in Kuwait) and the International Islamic Fiqh Academy on the basis of the agreement signed between them [11]. That shed light on diabetes and fasting at Ramadan and set the basis for informed

*Correspondence to: Imad eddin Rahamtalla Musa, Royal Commission Hospital at Jubail Industrial City, P.O.B. 11994, zip code 31961, KSA, E-mail: irthesudanese@hotmail.com

Key words: Islamic religion, fasting, Ramadan, diabetes mellitus

Received: January 31, 2020; Accepted: February 14, 2020; Published: February 19,2020 
individual decision based on the recommendations of physicians and religion scholars [11]. This is a step forward to reduce the differences between different religions schools, educate patients and increase awareness of healthcare providers in this field [15]. The influence of the Islamic religion extends beyond the exemption of sick people from fasting during Ramadan. Some healthy patients with diabetes mellitus may break the fast in certain circumstances when their lives are exposed to potential risk. The Islamic teachings have a positive contribution for patients with medical problems, especially those scattered in non-Muslim countries. Islamic religious teachings support medical recommendations regarding Ramadan fasting for patients with diabetes mellitus. Therefore, we can minimize the number of high-risk Muslims who used to fast before. For the importance of religious influence on decision to fast during Ramadan for patients of diabetes mellitus, which comprises a considerable number of people, I conducted a systematic review to evaluate the influence of the Islamic religion on Ramadan fasting for patients of diabetes mellitus to collect reasonable evidence for performing the divine commands in a safe environment.

\section{Method}

A systematic search of studies relating to diabetes mellitus during Ramadan fasting was performed between the $1^{\text {st }}$ of January 1990 and the end of February 2019, using the following databases: PubMed and the Google search engine. Using the words "religious", "fasting", "Ramadan" and "diabetes mellitus".

The electronic database search yielded 153 studies. One hundred and four studies were removed for not addressing the aim of the study, duplication, lacking proper citation, and not being within the period decided beforehand. Titles and abstracts were evaluated to determine eligibility for full screening. Studies that employed acceptable quantitative and/or qualitative methods, including randomized controlled trials, observational studies (e.g., cross-sectional, experimental, and interventional), review articles, ideas, editorials, and opinions were included. All studies on adherence to the role of religion for patients with diabetes mellitus during Ramadan fasting were eligible for inclusion. The summary of the literature search procedure is illustrated in Figure 1. Once all relevant studies had been identified, full-text manuscripts were retrieved for assessment. The studies were grouped according to the primary aims: discussing religious issues, reasons for fasting among high-risk groups, special cases, education and cooperation between religious leaders and healthcare providers. This enabled the identification of papers that addressed specific topics and issues relevant to our objectives, and facilitated the retrieval of information.

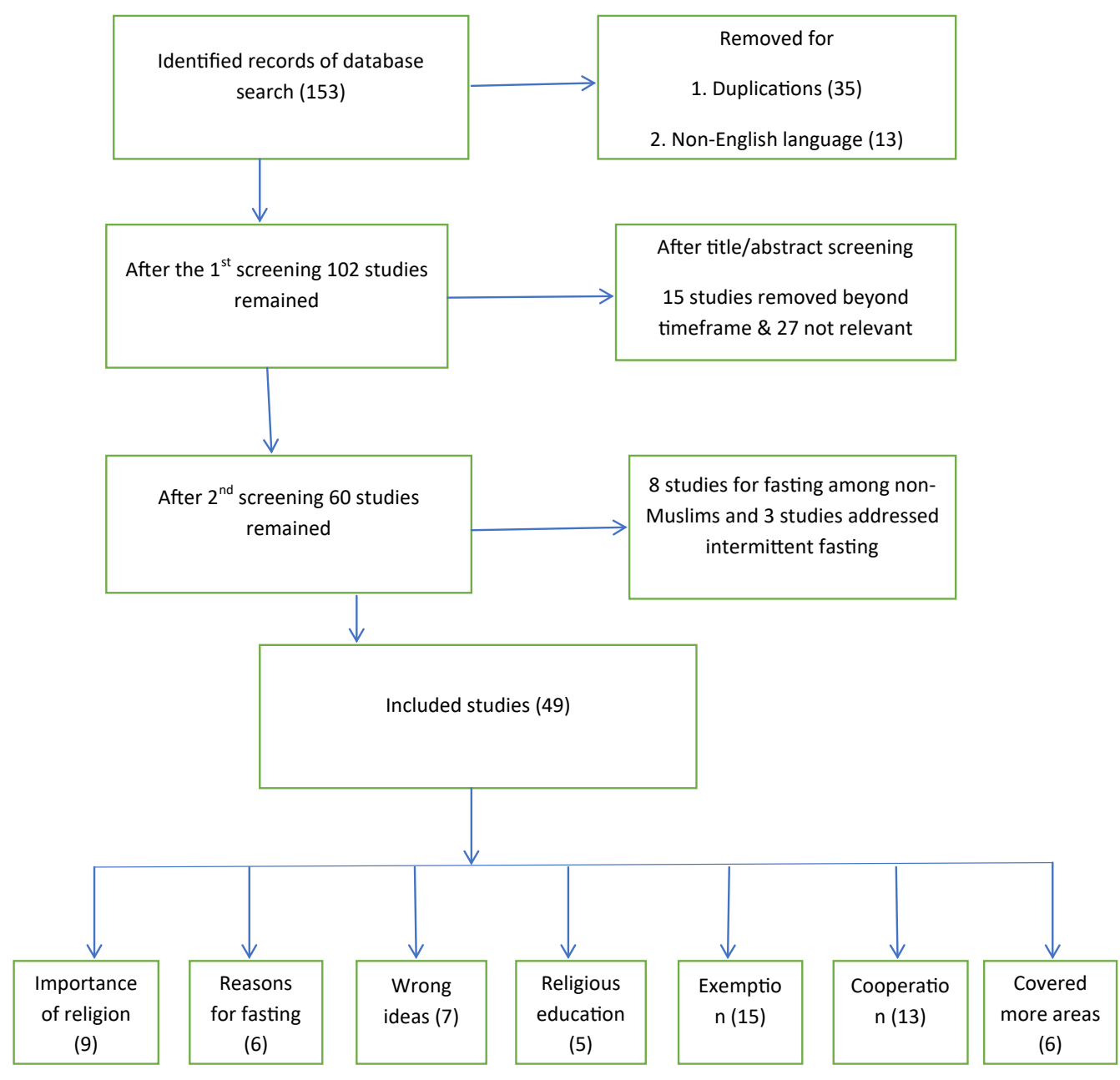

Figure 1. Shows the study selection process 


\section{Result}

A total of 143 citations were initially identified. One hundred and four studies were removed for not addressing the aim of the study, duplication, lacking proper citation, and poor use of language. After screening titles and abstracts, 49 full-text articles were retrieved for eligibility analysis. Nine studies focused on the importance and positive effects of religion on fasting for these patients [11,15-22] fifteen studies concentrated on the exemptions of patients with diabetes mellitus, six studies evaluated the reasons for fasting among exempted persons [2328] [5,12-15,29-38], seven studies stressed some wrong ideas about fasting [22,26,27,39-41], religious education (five studies) [42,43,47,4854] and cooperation between religious scholars and healthcare providers (thirteen studies) [15,23,42,43,46,48-53,55-59] Six studies touched more than one item $[15,23,25-27,43]$.

\section{Discussion}

In fact, the Islamic religion organizes and augments the medical recommendations regarding Ramadan fasting for patients with diabetes mellitus. Ramadan fasting is considered an act of spiritual faith by all Muslims; hence they are keen to fulfill this religious obligation. On the other hand, not all Muslims ought to fast as the Holy Quran states that some groups of people are exempted. [(Fasting) for a fixed number of days; but if any of you is ill, or on a journey, the prescribed number (Should be made up) from days later. For those who can do it (With hardship), is a ransom, the feeding of one that is indigent. But he that will give more, of his own free will,-it is better for him. And it is better for you that ye fast, if ye only knew.-Surah Baqarah 2:184] Likewise, Islam does not recommend Ramadan fasting for pregnant women and nursing mothers, people traveling during Ramadan, children and those who lack insight (e.g. people who are mentally ill or have an impaired level of consciousness) [12-14]. Women in menses or with post-natal bleeding are not allowed to fast too [12]. The main concept is that "Religion is a deeply personal matter, and its impact on illness is difficult to measure" $[16,17]$.

Many patients admit the importance of religion in their lives and expect their physicians to consider religious factors in their healthcare management [18] This was supported by most British general practitioners and American family physicians who recognized the potentially positive effect of religiosity on their patients' health [19-21]. These effects can be used to pave the road for safe fasting Ramadan and strengthen the patient-physician bond. Another study documented the fasting-related favorable effects on several health parameters such as blood pressure, blood lipids, insulin sensitivity, and biomarkers of oxidative stress [21]. These beneficial effects on healthy individuals were reported in a narrative review too [21]. Likewise, Muslims of higher religiosity achieved significantly better glycemic control [22]. Hence the religion aims to bridge the current knowledge gaps in the available evidence to improve the general outcome [14]. In fact many patients with diabetes mellitus prefer to fast during Ramadan to fulfill their religious obligation despite being advised by their doctors to avoid fasting [23]. While there are religious recommendations inconsistent with some verses of the Holy Quran and the prophet's sayings that focus on disease prevention and treatment, most of these patients are driven by some religious beliefs as they believe that they have strong faith and death is part of God's plan [24]. Hence they are willing to take the risk of fasting during Ramadan irrespective of the serious consequences and against medical and religious recommendations. Fatalism is another issue, which refers to a belief that "events are controlled and predetermined by the will of Allah (God) and that humans have little influence, if any control, over their destinies [24,25]. Another study found that many patients believed that only God could cure diabetes mellitus and not their doctors or medicines [25]. Old patients with diabetes are more adherent to fasting than people of the younger age groups, as they are accustomed to fasting since their youth. Performing their religious duty offers self-satisfaction and boosts their self-esteem as they share the Ramadan festive atmosphere with others [26]. Moreover, those who succeeded in fasting before without significant complications are likely to fast again, believing they have the condition under control [27]. These beliefs need to be handled in a proper way in order to minimize the number of patients with high risk to fast during Ramadan. Some patients do not accept the recommendations of physicians that discourage fasting for medical reasons because they believe that direction must come from religious leaders rather than physicians. These religious beliefs might not be understood or used in a potentially positive way even though most religions promote the common goals of spiritual attainment, well-being and body-mind integration [28]. Generally, all healthy Muslims after puberty are required to fast during Ramadan, except those who are sick, traveling, pregnant, nursing babies, menstruating, or in a debilitated $[29,30]$. These recommendations are based on the Holy Quran's instructions: "Therefore, whoever of you is present (at his home) during the month, he shall fast therein, and whoever is sick or on a journey, he shall then (fast) the same number of other days" Verse (2:185) sürat l-baqarah). In addition to the above, children below 12 and women who are menstruating or nursing a baby are exempted from Ramadan fasting according to Islamic laws. The Quran clearly points to the concept of the divine legislation on fasting during Ramadan at the end of the verse, and says: "Allah desires ease for you, and He does not desire hardship for you" Verse (2:185) sürat l-baqarah). The concept of the Holy Quran is clear and allows those who cannot tolerate fasting physically to break it [31]. Mercy is addressed in most verses of the Holy Quran, "And We did not send you (O Muhammad) except as a mercy for all creation". (21:107 Sūratu ' $l-A n b \bar{y} y \bar{a}$. The Quran specifically exempts the sick from fasting during Ramadan, which represents more than a simple permission to break the fast. This was strengthened by the Prophet Mohammad (PBUH), who said, "God likes his permission to be fulfilled, as he likes his will to be executed." However, the majority of Muslim patients insist on fasting against Islamic religious recommendations [5,32]. Hence fasting is a divine duty for safe and sound persons; likewise, not fasting is a divine command for exempted individuals and others with defined proper conditions to obey. Exemptions or dispensations are included in all Islamic doctrines when a necessity or need arises: A 'necessity' arises when an individual needs to violate Islamic teachings due to dire circumstances to directly safeguard religion, life, intellect, lineage, property and wealth and is considered to be one of the essential benefits of the flexibility of Islamic law [33-35]. Therefore, sick people or patients with high or higher risk during fasting are not encouraged to fast during Ramadan, including those with diabetes mellitus. The same applies to those who are working in certain jobs that carry the risk of acute complications related to fasting such as hypoglycemia. Driving for long distance during Ramadan, is associated with an increased risk of hypoglycemia and sleep-related road traffic accidents; hence drivers should avoid fasting as it is incompatible with the Islamic religion $[33,36]$. The same considerations are adopted for other jobs that require hard physical efforts such as workers who work under hot weather. Necessity is a chapter in the Islamic religion broader than its use to preserve life and avoid potential risks. While the average fasting period during Ramadan is 12 hours in length in most Islamic countries [37], it can be extended to 22 hours in some different areas, especially in polar 
regions and during summer time [38]. Fortunately, Islamic rules for Muslims, including stable patients with diabetes mellitus living in such regions, allow them to adopt the fasting period of either Mecca or the nearest temperate location [38]. This permission is sound and resolves the conflict created by some different Islamic doctrines where Muslims are minorities. Knowing these differences is a valid tool that would help healthcare providers explain to their Muslim patients all possible options using culturally competent information [15]. Many wrong or misunderstood ideas deserve more elaboration from the religious aspect to augment the medical advice. Medical advice is sometimes rejected for religious reasons: some devoted Muslims say, 'Everything in life is controlled by God's will', 'Allah will protect me', 'I am not scared of death or may even want to die so as to meet The God. Hence proper and effective counseling with sound explanations is of paramount value. In fact, patients being evaluated by a doctor and complying with treatment is a part of Prophet Mohammad's teachings, which is called sunnat (or precedent) and violation would be a sin [39]. While Muslims may be devoted, follower of certain doctrines, liberal or secular, health professionals are also human and may have negative feelings about Muslims. Therefore, assessing the religious depth carefully and ignoring the negative feelings will be reflected positively in medical care [15,39]. Moreover, breaking the fast is considered shameful and a social stigma; hence some patients with high risk are obliged to fast during Ramadan to avoid being labeled as non-believers or handicapped. Likewise, the society is intolerant as many people do not understand that some healthy-looking persons are really sick [26]. It is necessary for the religious leaders to clarify and resolve such wrong ideas for patients, healthcare providers and society through proper structural educational programs. On the same issue, one study showed that the decision to fast during Ramadan was influenced by familial pressure and the collective social aspect of fasting without referring to the proper personnel [27]. Surprisingly, most shops that serve food are closed during the fasting period in a considerable number of Islamic countries; this also forces some patients with a high risk to fast with others. Moreover, eating in public during the fasting period of Ramadan is considered a crime in some Islamic countries and may be penalized with whipping, imprisonment or a fine. Some patients with diabetes mellitus, who have exemptions not to fast, refuse to eat in public to avoid punishment or embarrassment. The role of religious leaders is to help educate the public from the religious aspect and negotiate with the governmental authorities to support and protect high-risk people and save private places for food intake during the fasting period. The social stigma among these patients with diabetes mellitus can affect adherence to medications and glycemic control because some patients avoid taking their medications in front of others [25]. Another misconception and popular belief is that pricking the finger to monitor blood sugar breaks the fast; hence some patients may neglect to monitor their glucose levels during Ramadan [40]. The same concept is applied to blood sample testing and insulin therapy despite having no nutritional elements [40]. Fortunately enough, these beliefs are very rare nowadays. These points deserve more attention from both religious leaders and healthcare providers to improve adherence to glucose self-monitoring and insulin therapy in order to reduce the risk of acute complications. While healthcare providers may be able to educate patients with diabetes mellitus regarding Ramadan fasting, religious leaders may influence individuals to follow their physicians' advice [41]. Healthcare providers lack the awareness of some basic religious teachings that may help to select the proper candidates among patients with diabetes mellitus to fast during Ramadan. This goes with a systematic review that explored the deficiencies in religious knowledge about fasting in
Ramadan among Muslim patients as well as among doctors [42], especially those working in some parts of America. They have limited knowledge about the specifics of fasting during Ramadan, therefore making it difficult for many Muslims to make informed decisions [43]. Given its pervasiveness, spirituality commonly affects patient encounters with their healthcare providers, as the patients usually expect their healthcare providers to inquire about their religious beliefs, pray with them and know their beliefs [44]. This attitude may make it easier for physicians to communicate their recommendations, with a high possibility of acceptance from their patients. On the other hand, physicians have identified many barriers to spiritual assessment: a lack of time, a lack of experience in taking spiritual history, difficulty identifying patients who wanted to discuss spiritual issues and the belief that addressing spiritual concerns is not a part of medical management [45]. On the contrary, education might aid in correcting myths or wrong beliefs related to managing diabetes mellitus and improving the general outcome [46]. Furthermore, recent studies have supported educational programs that involve religious leaders and healthcare providers with the aim of offering patients health advice that combines religious and medical directives [15,47,48]. Fasting during the holy month of Ramadan brings into focus the need to align medical safety with religious beliefs to bridge the gaps. Hence, a number of guidelines have been developed to cover this area [11,15,49-51]. The Fiqh Academy's decree started by defining the four main types of diabetes (type 1, type 2, other types and diabetes of pregnancy) in accordance with the World Health Organization and the American Diabetes Association criteria for diagnosing and classifying diabetes mellitus [52]. In 2005, the experts evaluated patients with diabetes mellitus for Ramadan fasting and released their recommendation after classifying them medically into four categories [53]: (I) very high risk of serious complications, (II) high risk of complications (poor glycemic control), (III) a medium risk of complications (stable situations and controlled by the appropriate oral hypoglycemic agents: insulin secretagogues, such as sulphonylureas) and (IV) low risk of complications (controlled by diet and non-insulin secretagogues [such as Metformin and Glitazones]) [11]. This was a landmark event that made fruitful recommendations. However, poor religious knowledge about Ramadan fasting and its management has been observed among some healthcare professionals [54]. Poor glycemic control is considered to be a high-to-very-high risk for fasting during Ramadan. Hence the recommendation is to avoid fasting [11,43,51]. Unfortunately, many reports showed a high prevalence of uncontrolled diabetes mellitus, especially in developing countries [55-57]. In this medical sitting, fruitful efforts are needed to control blood sugar earlier before Ramadan or to convince patients to break their fasting during it. This is a hot area for improvement that requires the synergistic action plans of medical and religious experts. Programs and healthcare journalists should offer focused educational programs prior to the month of Ramadan. Such joint interviews between expert doctors and religious scholars would offer clear and authoritative views and answer all commonly asked questions and inquiries [58]. Religious and traditional physicians have had more influence in permitting the breaking of fast compared to their secular colleagues (53\% and 25\%, respectively, $\mathrm{p}=0.01)$ [59]. Collaboration of healthcare providers and religious authorities should be extended to ensure patients receive adequate education before fasting during Ramadan [23]. Likewise, one study has shown that religious leaders are willing to include diabetes education within their teachings and lectures [48]. Therefore, it is important to have unification between religious leaders and healthcare providers for those with exemptions or dispensations. The risk stratification method is a 
powerful tool to classify patients according to their medical condition and possible risks associated with fasting to release confidential recommendations based on religious teachings and medical fitness $[11,51,53,58]$.

\section{Conclusion}

The role of religion is essential in this setting; hence exploration and activation are highly recommended. Moreover, the collaboration between healthcare providers and religious authorities should be encouraged to bridge the gaps between medical and religious issues in order to reduce the number of patients with diabetes mellitus who take the considerably high risk of engaging in fasting during Ramadan.

\section{Limitation}

This study used only Pubmed and Google database and timeframe, and some valuable data are not included. Another limitation is related to the article selection criteria that were used.

\section{Authors' contributions}

IR designed the study, gathered and entered the data, drafted the manuscript, revised the manuscript and finalized it.

\section{Acknowledgments}

None

\section{Competing interests}

I have no competing interests.

\section{Availability of data and materials}

The datasets used and/or analyzed during the current study are available from the database search engine.

\section{Consent for publication}

Not applicable.

\section{Ethics approval and consent to participate}

Not applicable.

\section{Funding}

None.

\section{References}

1. Internal diabetes federation (2015) IDF Diabetes Atlas 140.

2. Abdelgadir EIE, Hassanein MM, Bashier AMK, Abdelaziz S, Baki S, et al. (2016) A prospective multi-country observational trial to compare the incidences of diabetic ketoacidosis in the month of Ramadan, the preceding month, and the following month (DKAR international). J Diabetes Metab Disord 15: 50.

3. Tan C, Yong AML, Haji Mohamad MA, Abdul Rahman H, Naing L (2018) Fasting in Ramadan of Muslim patients with diabetes Mellitus, and knowledge and practice in relation to diabetes control in Brunei. Diabetes Res Clin Pract 144: 171-176.

4. Abid M, Hsairi M, Elleuch M, Ben Aissa E (2018) Survey on diabetic patients treated with insulin during the fasting month of Ramadan. Int J Gen Med 11: 33-40. [Crossref]

5. Salti I, Bénard E, Detournay B, Bianchi-Biscay M, Le Brigand C, et al. (2004) A population-based study of diabetes and its characteristics during the fasting month of Ramadan in 13 countries: results of the epidemiology of diabetes and Ramadan 1422/2001 (EPIDIAR) study. Diabetes Care. 27: 2306-2311.

6. Almalki MH, Hussen I, Khan SA, Almaghamsi A (2018) Assessment of Ramadan education and knowledge among diabetic patients. Clin Med Insights Endocrinol Diabetes 11: 1. [Crossref]
7. V RA, Zargar AH (2017) Diabetes control during Ramadan fasting. Cleve Clin J Med 84: 352-356. [Crossref]

8. Shao Y, Lim GJ, Chua CL, Wong YF, Yeoh ECK, et al. (2018) The effect of Ramadan fasting and continuing sodium-glucose co-transporter-2 (SGLT2) inhibitor use on ketonemia, blood pressure and renal function in Muslim patients with type 2 diabetes. Diabetes Res Clin Pract 142: 85-91. [Crossref]

9. Ajabnoor GMA, Bahijri S, Shaik NA, Borai A, Alamoudi AA, et al. (2017) Ramadan fasting in Saudi Arabia is associated with altered expression of CLOCK, DUSP and IL-1alpha genes, as well as changes in cardiometabolic risk factors. Oster H, editor. PLoS One 12: e0174342.

10. Bener A, Al-Hamaq AA, Öztürk M, Çatan F, Haris P, et al. (2018) Effect of ramadan fasting on glycemic control and other essential variables in diabetic patients. Ann Afr Med 17: 196.

11. Beshyah S (2009) Fasting during the month of Ramadan for people with diabetes Medicine and fiqh united at last. Ibnosina J Med Biomed Sci 1: 58.

12. Laway BA, Ashraf H (2015) Basic rules of Ramadan: A medico-religious perspective. J Pak Med Assoc 65: 14-7.

13. Khalife T, Pettit JM, Weiss BD (2015) Caring for Muslim patients who fast during Ramadan. Am Fam Physician 91: 641-642. [Crossref]

14. Persynaki A, Karras S, Pichard C (2017) Unraveling the metabolic health benefits of fasting related to religious beliefs: A narrative review. Nutrition 35: 14-20. [Crossref]

15. Abolaban H, Al-Moujahed A (2017) Muslim patients in Ramadan: A review for primary care physicians. Avicenna J Med 7: 81-87. [Crossref]

16. Eckersley RM (2007) Culture, spirituality, religion and health: looking at the big picture. Med J Aust 186: 54-56

17. Koenig HG (2004) Religion, spirituality, and medicine: research findings and implications for clinical practice. South Med J 97: 1194-1200. [Crossref]

18. Maugans TA, Wadland WC (1991) Religion and family medicine: a survey of physicians and patients. J Fam Pract 32: 210-213. [Crossref]

19. Murray SA, Kendall M, Boyd K, Worth A, Benton TF (2003) General practitioner and their possible role in providing spiritual care: a qualitative study. $\mathrm{Br} J$ Gen Pract 53: 957-959.

20. Puchalski CM, Larson DB, Lu FG (2000) Spirituality Courses in Psychiatry Residency Programs. Psychiatr Ann 30: 543-548.

21. Trepanowski JF, Bloomer RJ (2010) The impact of religious fasting on human health Nutr J 9: 57. [Crossref]

22. How CB, Ming KE, Chin CY (2011) Does religious affiliation influence glycaemic control in primary care patients with type 2 diabetes mellitus? Ment Health Fam Med 8: 21-28.

23. Lee JY, Wong CP, Tan CSS, Nasir NH, Lee SWH (2017) Type 2 diabetes patient's perspective on Ramadan fasting: a qualitative study. BMJ Open Diabetes Res Care 5: e000365. [Crossref]

24. Alsairafi ZK, Taylor KMG, Smith FJ, Alattar AT (2016) Patients' management of type 2 diabetes in Middle Eastern countries: review of studies. Patient Prefer Adherence 10: 1051-1062.

25. Jeragh-Alhaddad FB, Waheedi M, Barber ND, Brock TP (2015) Barriers to medication taking among Kuwaiti patients with type 2 diabetes: a qualitative study. Patient Prefer Adherence 9: 1491-1503. [Crossref]

26. Azzoug S, Mahgoun S, Chentli F (2015) Diabetes mellitus and Ramadan in elderly patients. J Pak Med Assoc 65: S33-36. [Crossref]

27. Patel NR, Kennedy A, Blickem C, Rogers A, Reeves D, et al. (2015) Having diabetes and having to fast: a qualitative study of British Muslims with diabetes. Heal Expect 18: 1698-1708.

28. Venegas-Borsellino C, Sonikpreet, Martindale RG (2018) From Religion to Secularism: the Benefits of Fasting. Curr Nutr Rep 7: 131-138.

29. Bernieh BO, Mohamed AO, Wafa AM (1994) Ramadan fasting and renal transplan recipients: Clinical and biochemical effects. Saudi J Kidney Dis Transpl 5: 470-473.

30. Kadri N, Tilane A, El Batal M, Taltit Y, Tahiri SM, et al. (2000) Irritability during the month of Ramadan. Psychosom Med 62: 280-285. [Crossref]

31. Aziz El-Sayed AA, Sabet EA (2015) Fasting Ramadan in diabetic patients: When is fasting not advisable in a person with diabetes? J Pak Med Assoc 65: S22-25. [Crossref] 
32. Meo SA, Hassan A (2015) Physiological changes during fasting in Ramadan. $J$ Pak Med Assoc 65: 6-14.

33. Ghouri N, Hussain S, Mohammed R, Beshyah SA, et al. (2018) Diabetes, driving and fasting during Ramadan: the interplay between secular and religious law. BMJ Open Diabetes Res Care 6: e000520. [Crossref]

34. Gatrad AR, Sheikh A (2001) Medical ethics and Islam: principles and practice. Arch Dis Child 84: 72-75. [Crossref]

35. Kamali MH (2003) Islamic Texts Society. Principles of Islamic jurisprudence. Third revised and enlarged edition. Cambridge: Islamic Texts Society.

36. Al-Houqani M, Eid HO, Abu-Zidan FM (2013) Sleep-related collisions in United Arab Emirates. Accid Anal Prev 50: 1052-1055. [Crossref]

37. Benli Aksungar F, Eren A, Ure S, Teskin O, Ates G (2005) Effects of Intermittent Fasting on Serum Lipid Levels, Coagulation Status and Plasma Homocysteine Levels. Ann Nutr Metab 49: 77-82.

38. Leiper JB, Molla AM, Molla AM (2003) Effects on health of fluid restriction during fasting in Ramadan. Eur J Clin Nutr 2: 30-38. [Crossref]

39. Qureshi B (2002) Diabetes in Ramadan. J R Soc Med 95: 489-490. [Crossref]

40. Ibrahim M, Al Magd MA, Annabi FA, Assaad-Khalil S, et al. (2015) Recommendations for management of diabetes during Ramadan. Update 3: e000108.

41. Al Slail FY, Afridi HU, Fadl SM, Kheir OO (2015) Levels of health awareness in diabetic patients during Ramadan 2015: Focus group discussion in Riyadh, Saudi Arabia. J Epidemiol Glob Health 7: 49-54.

42. Ilkilic I, Ertin H (2017) Ethical conflicts in the treatment of fasting Muslim patients with diabetes during Ramadan. Med Health Care Philos 20: 561-570. [Crossref]

43. Bajaj HS, Abouhassan T, Ahsan MR, Arnaout A, Hassanein M, et al. (2019) Diabetes Canada Position Statement for People With Types 1 and 2 Diabetes Who Fast During Ramadan. Can J Diabetes 43: 3-12. [Crossref]

44. MacLean CD, Susi B, Phifer N, Schultz L, Bynum D, et al. (2003) Patient preference for physician discussion and practice of spirituality. J Gen Intern Med 18: 38-43. [Crossref]

45. Ellis MR, Vinson DC, Ewigman B (1999) Addressing spiritual concerns of patients: family physicians' attitudes and practices. J Fam Pract 48: 105-109.

46. Rai M, Kishore J (2009) Myths about diabetes and its treatment in North Indian population. Int J Diabetes Dev Ctries 29: 129-132.
47. Myers PR, Shoqirat N, Allen DH, Dardas LA (2019) Patients with diabetes observing Ramadan: The experience of Muslims in the United States. Diabetes Res Clin Pract 8: 0168-8227.

48. Grace C, Begum R, Subhani S, Kopelman P, Greenhalgh T (2008) Prevention of type 2 diabetes in British Bangladeshis: qualitative study of community, religious, and professional perspectives. BMJ 337: a1931. [Crossref]

49. Pathan MF, Zargar A, Azad Khan A, Siddiqui N, Ishtiaq O, et al. (2012) South Asian Consensus Guideline: Use of insulin in diabetes during Ramadan. Indian J Endocrinol Metab 16: 499.

50. Chandalia H (2006) Ramadan fast and control of diabetes. Int J Diabetes Dev Ctries 26: 49

51. Hassanein M, Al-Arouj M, Hamdy O, Bebakar WMW, Jabbar A, et al. (2017) Diabetes and Ramadan: Practical guidelines. Diabetes Res Clin Pract 126: 303-316. [Crossref]

52. American Diabetes Association (2009) Diagnosis and classification of diabetes mellitus. Diabetes Care 3: 62-67.

53. Al-Arouj M, Bouguerra R, Buse J, Hafez S, Hassanein M, et al. (2005) Recommendations for management of diabetes during Ramadan. Diabetes Care 28: 2305-2311. [Crossref]

54. Gaborit B, Dutour O, Ronsin O, Atlan C, Darmon P, et al. (2011) Ramadan fasting with diabetes: an interview study of inpatients' and general practitioners' attitudes in the South of France. Diabetes Metab 37: 395-402. [Crossref]

55. Omar SM, Musa IR, Osman OE, Adam I (2018) Assessment of glycemic control in type 2 diabetes in the Eastern Sudan. BMC Res Notes 11: 373. [Crossref]

56. Noor SK, Elmadhoun WM, Bushara SO, Almobarak AO, Salim RS, et al. (2017) Glycaemic control in Sudanese individuals with type 2 diabetes: Population based study. Diabetes Metab Syndr Clin Res Rev 11: S147-51

57. Musenge EM, Michelo C, Mudenda B, Manankov A (2016) Glycaemic control and associated self-management behaviours in diabetic outpatients: A hospital based observation study in Lusaka, Zambia. J Diabetes Res 2: 1-9.

58. Beshyah S, Benbarka M, Sherif I (2007) Practical management of diabetes during Ramadan fast. Libyan J Med 2: 185-189.

59. Adler-Lazarovits C, Weintraub AY (2019) Physicians' attitudes and views regarding religious fasting during pregnancy and review of the literature. Eur J Obstet Gynecol Reprod Biol 233: 76-80. [Crossref]

Copyright: (C2020 Musa IR. This is an open-access article distributed under the terms of the Creative Commons Attribution License, which permits unrestricted use, distribution, and reproduction in any medium, provided the original author and source are credited. 